\title{
Corrigendum: Effect of Acetaminophen Ingestion on Thermoregulation of Normothermic, Non-febrile Humans
}

\author{
Josh Foster ${ }^{1}$, Alexis Mauger ${ }^{2}$, Katie Thomasson ${ }^{1}$, Stephanie White ${ }^{1}$ and Lee Taylor ${ }^{3,1 *}$ \\ ${ }^{1}$ Applied Sport and Exercise Physiology Research Group, Department of Sport Science and Physical Activity, Institute of \\ Sport and Physical Activity Research, University of Bedfordshire, Bedford, UK, ${ }^{2}$ Endurance Research Group, School of Sport \\ and Exercise Sciences, University of Kent, Chatham Maritime, Kent, UK, ${ }^{3}$ ASPETAR, Qatar Orthopaedic and Sports \\ Medicine Hospital, Athlete Health and Performance Research Centre, Doha, Qatar
}

Keywords: acetaminophen, paracetamol, tylenol, thermoregulation, temperature, therapeutichypothermia

\section{A corrigendum on}

Effect of Acetaminophen Ingestion on Thermoregulation of Normothermic, Non-febrile Humans

OPEN ACCESS

Edited and reviewed by:

Chiranjib Chakraborty,

Galgotias University, India

*Correspondence:

Lee Taylor

lee.taylor@aspetar.com

Specialty section:

This article was submitted to

Experimental Pharmacology and Drug

Discovery,

a section of the journal

Frontiers in Pharmacology

Received: 21 March 2016

Accepted: 22 March 2016

Published: 05 April 2016

Citation:

Foster J, Mauger A, Thomasson K,

White $S$ and Taylor L (2016)

Corrigendum: Effect of

Acetaminophen Ingestion on

Thermoregulation of Normothermic,

Non-febrile Humans.

Front. Pharmacol. 7:93

doi: 10.3389/fphar.2016.00093 by Foster, J., Mauger, A., Thomasson, K., White, S., and Taylor, L. (2016). Front. Pharmacol. 7:54. doi: 10.3389/fphar.2016.00054

Due to a misunderstanding, the requirements of the funding institution, Aspetar, regarding the affiliation order were not followed during production. In the original article, Lee Taylor's affiliation was affiliated with institutions " 1,3 " in that order.

According to the requirements of the funding institution, Dr. Taylor should be affiliated with Aspetar first and so it should be " 3,1 ."

The authors apologize for this. This error does not change the scientific conclusions of the article in any way.

The original article has been updated.

\section{AUTHOR CONTRIBUTIONS}

JF, LT, and AM contributed to the study design, data interpretation and manuscript revision. JF, KT, and SW contributed to data collection and also contributed to manuscript revision. All aspects of the project were supervised by LT, and AM. All authors approved the final version of the manuscript and all authors qualifying for authorship are listed.

Conflict of Interest Statement: The authors declare that the research was conducted in the absence of any commercial or financial relationships that could be construed as a potential conflict of interest.

Copyright () 2016 Foster, Mauger, Thomasson, White and Taylor. This is an open-access article distributed under the terms of the Creative Commons Attribution License (CC BY). The use, distribution or reproduction in other forums is permitted, provided the original author(s) or licensor are credited and that the original publication in this journal is cited, in accordance with accepted academic practice. No use, distribution or reproduction is permitted which does not comply with these terms. 